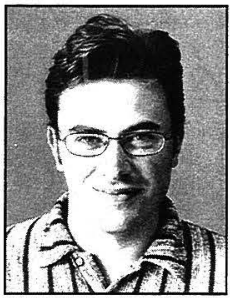

\title{
MAPPING SOCIAL EXCLUSION: THE GEOGRAPHY OF UNEMPLOYMENT
}

\author{
Paul Soldera \\ Institute of Geography \\ School of Earth Sciences \\ Victoria University of Wellington
}

\begin{abstract}
This paper analyses the relationship between the spatial distribution of unemployment in an urban area and economic growth. According to the hysteresis argument inertias build up in recessions that are not dispelled during periods of growth. The most common manifestation is the continued growth of long-term unemployment. Long durations of unemployment reduce skill levels, confidence, contacts and the chances of regaining paid work. This paper examines the possibility that these duration effects are also tied to the spatial distribution of unemployment, generating a form of spatial hysteresis. According to this argument clusters of unemployment that grow during recessions fail to shrink during periods of growth. These spatial concentrations of unemployment create a range of negative externalities that inhibit individuals in their search for employment. Using a GIS applied to census data a clustering statistic was employed to analyse the changing spatial distribution of the unemployed in the Wellington metropolitan regions over the period 1986 to 1996. Statistically significant clusters that persisted over the decade strongly support the spatial hysteresis argument.
\end{abstract}

Keywords: unemployment, spatial hysteresis, clustering, social exclusion.

This paper presents a case for the existence of spatial hysteresis: a condition whereby geographic clusters of unemployed form during recessions but are not dissipated during subsequent periods of growth. These clusters reinforce the breakdown in networks linking employment opportunities with the unemployed. As these negative externalities become cumulative so the chances of the unemployed finding work within these clusters diminish. The result we suggest is a form of social exclusion.

The paper begins by outlining the concept of social exclusion as it is presented in the literature. The second section introduces the relationship between hysteresis and neighbourhood effects. The method of identifying clusters is described and the results presented. The conclusion draws the finding together and is followed by a discussion of possible future research opportunities.

\section{Social and economic exclusion}

A great deal of concern and attention has been given to the notion that certain disadvantaged groups in society have become increasingly socially, economically and spatially isolated (Wilson, 1987; Mead, 1991; Borooah \& Hart, 1995; Gregory \& Hunter, 1995). In almost all cases this isolation rises from a lack of participation in the labour market. Whereas forty years ago it was the differences in income that constituted the largest single factor in determining the gap between the best and worst off in society, today it is differences in employment that contribute most to this gulf (Gregory \& Hunter, 1995; Mead, 1991).

In his 1987 book The Truly Disadvantaged Wilson showed that it was not the overall rate of unemployment that was the problem but the way in which this rate was distributed. Wilson documented the rising problem of non-work that accompanied the extreme poverty in the inner-city areas of the industrial north-east of the United States and revealed an environment in which spatially concentrated unemployment had effectively isolated and excluded a minority from the world of work. Similar fears have been expressed about the growing social, economic, and spatial isolation of other areas including the UK (see McGregor \& McConnachie, 1995,) Australasia (see Gregory \& Hunter, 1995; Murphy \& Watson, 1994; and Callister, 1997).

It is this concentration of unemployment and the associated poverty that are at the centre of the debate over social and economic exclusion. This debate has been rekindled in the US in the 1990's by Mead (1991) who argued that contemporary poverty is fundamentally different from that on which most US anti-poverty programs had originally been based.

Conceptualising this contemporary poverty is extremely difficult. Many researchers attempt to explain it in terms of 
an emerging underclass, from the educationally disadvantaged to the impoverished and jobless (Jenks, 1991), to the undeserving poor living off welfare (Murray, 1990). However, Macdonald (1997), in the British context, came to the conclusion that although there was a lack of consensus of what did and did not constitute the underclass in the UK, there remains nevertheless;

" a social group or class of people located at the bottom of the class structure who, over time, have become structurally separate and culturally distinct from the regularly employed working-class and society in general through processes of social and economic change (particularly de-industrialisation) and/or through patterns of cultural behaviour, who are now persistently reliant on state benefits and almost permanently confined to living in poorer conditions and neighbourhoods"

(MacDonald, 1997: 3)

Playing a central role in both the historical evolution of the concept of social exclusion and its relationship to changes in the labour market is the spatial distribution of the unemployed. From MacDonald's (1997) 'poorer conditions and neighbourhoods' to Wilson's (1987) inner-city ghettos, Hughes (1989) reconceptualised 'impacted ghetto', and Green's (1996) spatially concentrated 'losers', each definition carries with it the idea of a geographical demarcation between mainstream society and those marginal or separate from it. In the American context, Hughes (1989) went so far as to suggest that any definition of the underclass without reference to its spatial manifestation in the innercity was seriously flawed.

While in the UK, Europe, and Australasia inner-city areas do not show the type of depravation experienced in American ghettos, spatially demarcated concentrations of unemployment and poverty do exist. In the UK these are most evident in the declining industrial areas of the north yet in the south London is also described as having an expanding 'core' of disadvantage (Green, 1995). In Europe Kloosterman (1994) documented the demise of the outer lying suburbs of Amsterdam; Dandschat (1994) the old public housing areas of inner and outer Hamburg; Neef (1993) the degraded condition of a formally working class neighbourhood of Duisburg, Germany; and Wacquant (1993) the social consequences of living in the run-down suburb of La Courneuve in Paris. In Australia Baum and Hassan (1993) researched the declining areas of outer Adelaide and Fagan (1986) documented the concentrated deprivation of the western suburbs of Sydney. The commonalties between these studies are striking; in every case the poorer areas had large concentrations of unemployment or lack of labour market participation, many of the deprived areas were formally centres of manufacturing employment, and nearly all had large expanses of public authority or state housing.

Although the increasing spatial concentration of the unemployed is now well documented, few have researched the actual mechanisms by which these concentrations arise, persist, and increase except to observe that these clearly involve the interactions between the labour market, the housing market, and industrial change. What many researchers have agreed on however, is that concentrations of non-work may have a detrimental effect on the ability of residents to search for and retain employment. It is the likelihood that concentrations of unemployment retard labour adjustment that has attracted the attention of New Zealand's policy. This idea can be built around the concept of spatial hysteresis.

\section{Hysteresis and neighbourhood effects}

In macroeconomic theories of hysteresis, long-spells of high unemployment are said to affect the natural rate of unemployment through the duration effects associated with longterm unemployment and the subsequent under-representation of the long-term unemployed in the wage bargaining process (Blanchard \& Summers, 1987). In a spatial sense hysteresis may also occur if areas high in unemployment develop externalities that hinder the search and attainment of work by local residents. These externalities are commonly referred to as 'neighbourhood effects'. In these areas unemployment is not so much determined by the economic cycle (although this will have an impact) but by previous levels of unemployment.

The study of 'neighbourhood effects' has a long history in sociological and psychological discourse. Its central argument is that above and beyond the effects that immediate family and nonlocal friendship networks have on individuals, neighbourhoods can influence life choices and the distribution of opportunity. The idea is that environmental factors associated with the neighbourhood affect psychological well-being, self-esteem, self assessment, perceived social position, job search behaviour, employment opportunities, work habits and work ethic.

The connections are not simple however, for there are many potentially confounding variables involved in the study of neighbourhood effects. It is difficult to control for the influence of family and non-local social networks; statistical measurements of neighbourhoods do not necessarily represent how neighbourhoods define themselves; and implicit in many of the studies is the notion that spatial proximity promotes social interaction - which is not always the case. Notwithstanding all the difficulties in its use, the concept of neighbourhood effects remains central to the concept of spatial hysteresis.

The purpose of this study is not to explicitly analyse the relationship between neighbourhood and labour market adjustment, but rather to examine whether spatial concentration of the unemployed behave in ways consistent with the concept of spatial hysteresis. Specifically, if hysteresis was present then we would expect the process by which the unemployed cluster geographically within cities as unemployment rises is not simply reversed when unemployment falls. Rather, such clusters remain and show much slower rates of de-clustering or dissipation than one would expect from a reduction in the unemployment rates. 


\section{Analysis of unemployment clusters}

In New Zealand very little attention has been given to intra-urban differences in unemployment yet these differences are as substantial or larger than any division by ethnicity or sex and much greater than any variations over time. In 1996 in Auckland, the suburb of Ferguson, for example, had the highest unemployment rate, 25.61 percent, compared to the lowest in Hobsonville at only 2.47 percent - a range of 23.13 percent. If the unemployed in Auckland are divided between the three main ethnic groups European, Maori, and Pacific Islanders (with unemployment rates of 4.37, 14.67, and 15.70 percent respectively) the range is 11.33 percent. Wellington's suburban unemployment is similar. Even over the post war period New Zealand's unemployment rate has only experienced about the same range, from under one percent to a maximum of 10.7 percent (Sept. 1991; Mare 1997: 13).

Within the census, suburbs are approximated by statistical areas called 'area units' yet these areas are in no sense representative of neighbourhoods as social or spatial constructs. Area units normally contain upwards of 1,500 people with many typically holding in excess of three or four thousand. These are too large and statistics collected at the area unit level may well aggregate important local variations. For these reasons smaller units called 'meshblocks' were chosen in this study as the basic 'neighbourhood unit'. Meshblocks are the smallest spatial division or unit on which census data is released (they generally have a median population of around 90) and although they are also arbitrary spatial units, neighbourhoods however defined can be more closely approximated by joining contiguous meshblocks that share common characteristics.

In this study meshblocks were used to identify sets of contiguous areas which had high unemployment rates. A measure from a group of statistics called Local Indicators of Spatial Association (LISA) was used to identify clusters based on both contiguity and a given level of unemployment. ${ }^{1}$ The statistic was programmed into ARCInfo (a geographic information system) and calculated for various levels of unemployment in the Wellington (and Auckland) greater metropolitan areas for the census years 1986, 1991, and $1996 .{ }^{2}$ The statistic was used to measure both the change in the spatial extent of unemployment and the intensity of the spatial clustering for each of the census years.

The two inter-census periods are significant because they cover a period of recession (1986-91) and a period of growth (1991-96). In a recessionary period one would not only expect unemployment rates across a city to rise but also for these rates to cluster in certain areas because specific types of employment, particularly low skilled employment, will be affected first. During a period of recovery unemployment rates across the city would be expected to fall as higher demand for goods and services gradually translates itself into a higher demand for labour. However, if certain areas retain high rates and the clusters of unemployment do not dissipate through periods of growth, this would constitute evidence in support of the process of spatial hysteresis.

\section{Results}

In 1986 all meshblocks with unemployment rates greater than 20 percent were chosen either as possible centres of clusters or as possibly belonging to a larger cluster of unemployed ${ }^{3,4}$ The clustering statistic was then run for each of these meshblocks at seven iterations of 150 metres from the meshblock's centroid. This process was repeated for meshblocks with greater than 20 percent unemployment in 1991 and 1996.

The extent of the cluster was defined as the distance at which the value of the statistic began to decline. When this occurs the additional meshblocks that are incorporated into the statistic at the given iteration are less in sum (of unemployment rates) than would be expected at the mean value for the city as a whole and thus clustering begins to decrease.

In total, for the Wellington region, 4,473 individual statistics were generated representing some 213 meshblocks over three census years and seven different distance iterations. In 1986, of the 53 meshblocks used as centres, 27 were significant at the .05 level. ${ }^{4}$ Of these however, only a handful represented individual clusters of unemployed as many overlapped in areas of high unemployment. In 1991 an additional 65 meshblocks were analysed for significance and in 1996, an additional 95 were investigated. The resulting patterns of clustering over the three census years is represented in Figure 1 (next page).

Figure 1 clearly shows that clustering increases between 1986 and 1991 when the unemployment rate for Wellington rose from 5.5 percent to 8.7 percent, yet when the unemployment rate dropped to 7.5 percent in 1996 only two smaller clusters disappeared while the remainder increased in intensity and in the case of the Naenae/Taita cluster, expanded outward. The Cannons Creek/Porirua East area is identified as a significant cluster in each census year. This cluster does not expand over the decade due in most part to the fact that the area is geographically constrained by hills in the north and southeast and by State Highway 1 to the west. The area is essentially 'saturated' with unemployment in each census year with no oppourtunity for this unemployment to spill into adjacent suburbs.

Through the 1986-91 recessionary period five new clusters of unemployment emerged. Three of these clusters were relatively small (extending between 450 and 600 metres from the central meshblock) and were confined to the areas of Titahi Bay, Upper Willis St, and Adelaide. The largest new spatially contiguous cluster emerged in Naenae, while the cluster to the north (shown in Figure 1 as one connected area) was actually two clusters; one in Delaney and one in Taita North.

During the 1991-96 recovery it might have been expected that the clusters of unemployed would have at least decreased in size or lost significance as unemployment in the city as a whole fell. As the 1996 map in Figure 1 reveals however, this only happened in two areas - Titahi Bay and Upper Willis St. Far from shrinking as unemployment rates 
Figure 1. Meshblock Clusters of unemployment for Wellington, 1986, 1991, 1996.

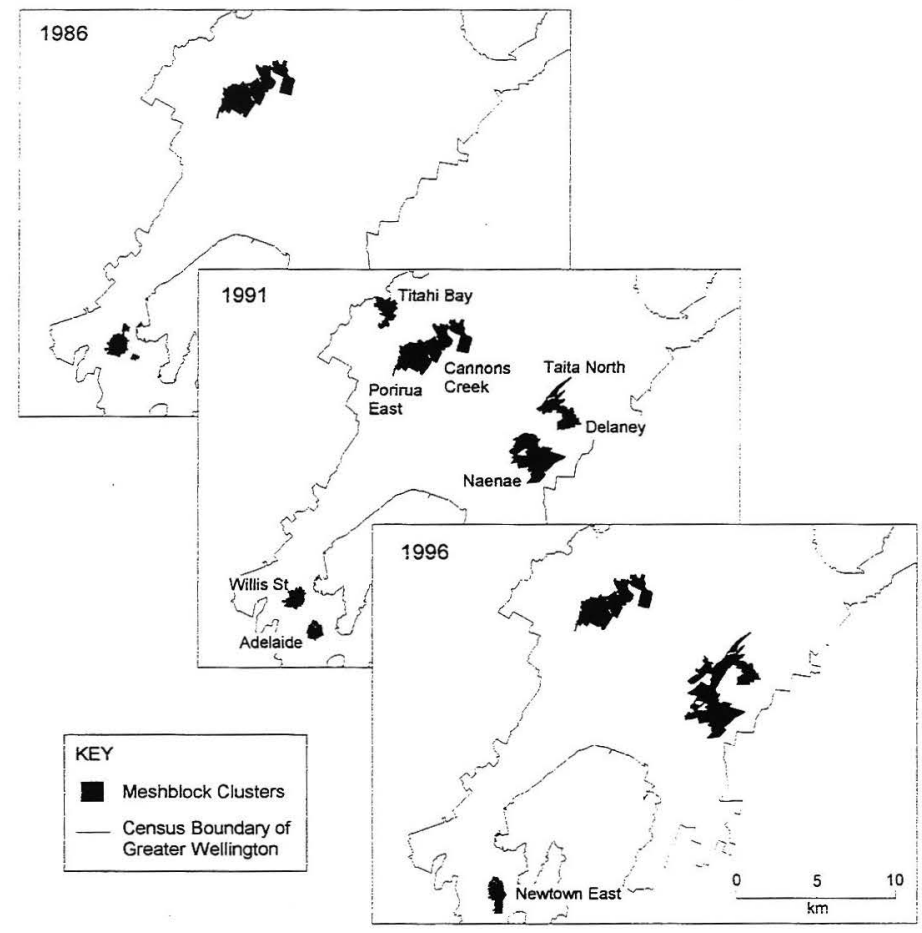

fell between 1991 and 1996, in Naenae the cluster expanded both north and south into adjacent meshblocks and became connected to the Taita North cluster while the cluster in Adelaide expanded into sections of Newtown East and West. These two examples are consistent with the operation of spatial hysteresis.

In addition to the spatial expansion of the clusters, their intensity also changed and may be used as further evidence of spatial hysteresis. The value of the statistic indicates the level of clustering compared to the level expected for Wellington as a whole and therefore tracks changes in intensity that are sensitive to city wide unemployment. If the recession of 1986-91 bought about an even increase in the unemployment rate over all meshblocks the actual intensity of the existing clusters would not change; even though unemployment in these areas would be higher, it would not be higher than what would be expected given the eco- nomic slowdown. The clusters did however, receive a higher than expected unemployment rate and as a consequence their intensities rose. The median intensity of the statistic in 1986 for all 1996 meshblock clusters was 3.29, in 1991 this rose to 6.00 and in 1996 rose again to 7.42 .

If the clusters are broken down into smaller clusters, an interesting pattern of changing intensities arises. In the Porirua/Cannons Creek area in 1986 the intensity of clustering was 12.71 , reflecting the fact that Porirua/Cannons Creek contains some of the highest and most spatially concentrated unemployment in the Wellington Region. During the recessionary period of 1986-91 however, the intensity of clustering in the area dropped to 11.83 implying that in 1991 the Porirua/Cannons creek area had a lower spatial intensity of unemployment than it had five years early. This is not because the area's unemployment situation improved however, it simply means that the area did 
not become any worse off when compared to the unemployment distribution for Wellington as a whole. In 1996 however, the intensity of unemployment clustering as measured by the statistic jumped to 17.25 , indicating that during the five year recovery period the intensity of clustering in the Porirua/Cannons Creek area worsened considerably.

It is worth emphasising that during the recessionary period the relative positions of the different areas of clustering did not change. The greatest change in the spatial differences in the unemployment rates occurred during the recovery phase, 1991-1996.

This failure of unemployment rates in certain areas to fall at the same rate as those for the city as a whole is well illustrated by the raw meshblock data for the Naenae area, (Figure 2). In 1986 unemployment rates were quite low across the entire area. However, by 1991 these rates rose almost everywhere with the beginnings of a cluster emerging to the east (see Figure 2). In 1996 rates in much of the area fell but not in the east, the north east, and the south west where they actually increased resulting in an increase in the intensity of clustering and hence in the spatial disparity across the area.

Labour force data for each 1996 cluster was also aggregated and analysed over the three census years and compared to the rest of the Wellington region (Table 1). On every single indicator of labour market performance the clustered regions performed progressively worse in each census year. This is perhaps the most important finding. One might have expected that in a period of economic growth as experienced throughout the early 1990's unemployment would have fallen in all areas. While aggregate rates did fall there occurred at the same time increasing spatial disparities in labour market performance across the different residential areas. The clustered area's median unemployment rate doubled over the decade while the rest of Welling experienced a slight increase from 4.35 to 5.88 percent (Table 1). What's more, during the growth period of 1991-1996 the median unemployment rate in the clustered areas rose by 2.38 percentage points while the rate for the rest of Wellington dropped by .79 points.

The change in these rates was not a result of underlying population movements. Firstly, in the ten year period 198696 the working-age population in the clustered areas dropped by only 1,128 people yet in the same time span the number of labour force participants fell by 4,320. This also corresponded with an increase of 802 in the absolute numbers of unemployed (Table 1). Progressively fewer and fewer people in the clustered areas were employed or participated in the labour force. In addition, the median hours worked per meshblock fell 12.4 percent compared to 2.0 percent for the rest of Wellington and real incomes decreased by 13.9 percent compared the rest of Wellington's 0.3 percent gain.

Secondly, there is little evidence that the unemployed from the rest of Wellington were moving to the clusters. Figure 3 shows there is no greater turnover of the population of the clustered areas than in Wellington as a whole.

The differential mobility experience does not exhaust the range of alternative reasons for the increase in clustering; it is possible that answer lies within the age, ethnic, and educational structure of those living in the clustered areas. In Wellington as a whole the vast majority of the unemployed are European (69.9 percent), then Maori (21.4 percent) and finally Pacific Islanders ( 9.0 percent). In the clustered areas however, the respective proportions are 30.43 percent, 30.56 percent, and 39.02 percent.

If these figures are broken down even further, into actual unemployment rates for each ethnic group, some interesting facts come to light. Table 2 shows that the trend of the overall unemployment rate in the clustered areas is reflected in the rates for each ethnic group but more so in the rate for

Table 1. Labour force characteristics for the clustered areas and remainder of the Wellington region

\begin{tabular}{|c|c|c|c|c|c|c|}
\hline & \multicolumn{2}{|c|}{1986} & \multicolumn{2}{|c|}{1991} & \multicolumn{2}{|c|}{1996} \\
\hline & Clusters & Wgtn. & Glisters & Wgtn. & Glusters: & Wgtn. \\
\hline $\begin{array}{l}\text { Median Usual Resident Population } \\
\text { (15 years and older) }\end{array}$ & 99 & 102 & 99 & 102 & 975 & 105 \\
\hline Number of unemployed & 1,002 & 7,428 & 2,559 & 11,385 & 2709 & 9,984 \\
\hline Median unemployment rate (percent) & 833 & 4.35 & 1429 & 6.67 & 1667 & 5.88 \\
\hline $\begin{array}{l}\text { Median number of labour force } \\
\text { participants }\end{array}$ & 48 & 60 & 42 & 57 & 36 & 57 \\
\hline $\begin{array}{l}\text { Median labour force participation } \\
\text { rate (percent) }\end{array}$ & 49.23 & 57.89 & 43.97 & 57.41 & 49 & 55 \\
\hline Median hours worked per week & -2 & - & 2595 & 35.22 & 22.71 & 34.5 \\
\hline $\begin{array}{l}\text { Median household income (1996 } \\
\text { prices) }\end{array}$ & 34,347 & 46,841 & 29,580 & 47,880 & 29,225 & 47,000 \\
\hline
\end{tabular}


Figure 2. Unemployment rates for meshblocks in the Naenae area, 1986, 1991, and 1996

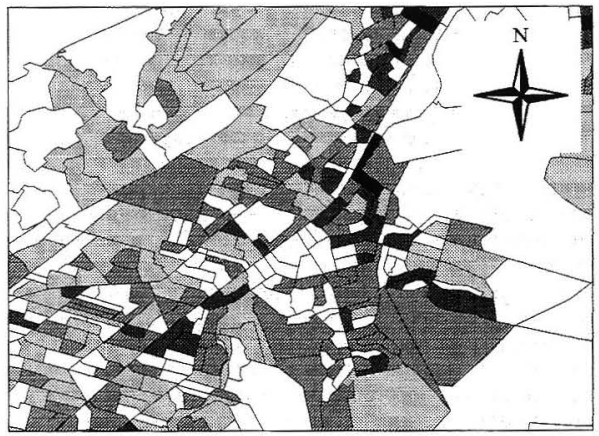

1986

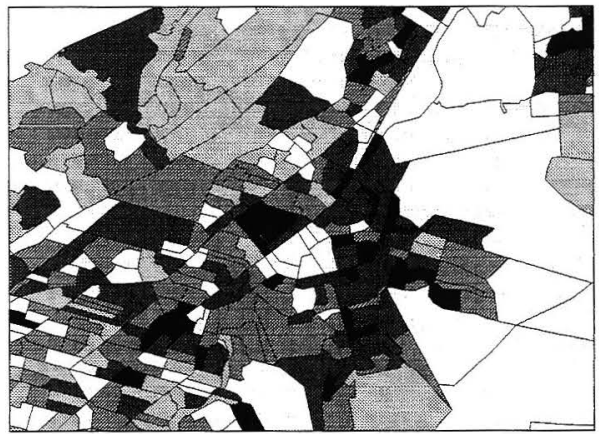

1991

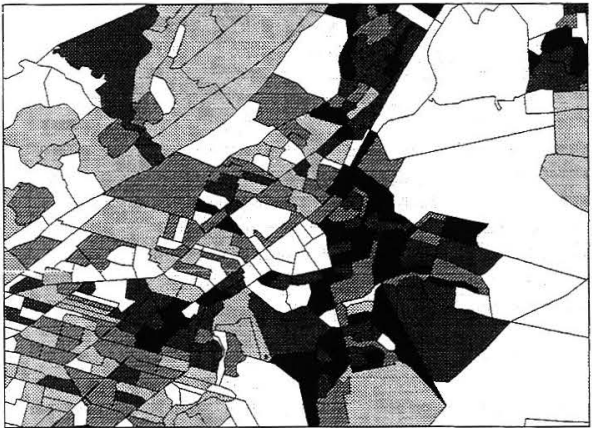

1996

Unemployment Rates

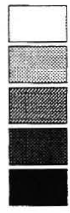

$0-2.17$

$2.17-6.15$

$6.15-10.53$

$10.53-17.78$

$17.78+$ 
Figure 3. Duration of residential residence profile for the clustered areas vs. the remainder of the Wellington region (percent) ${ }^{5}$

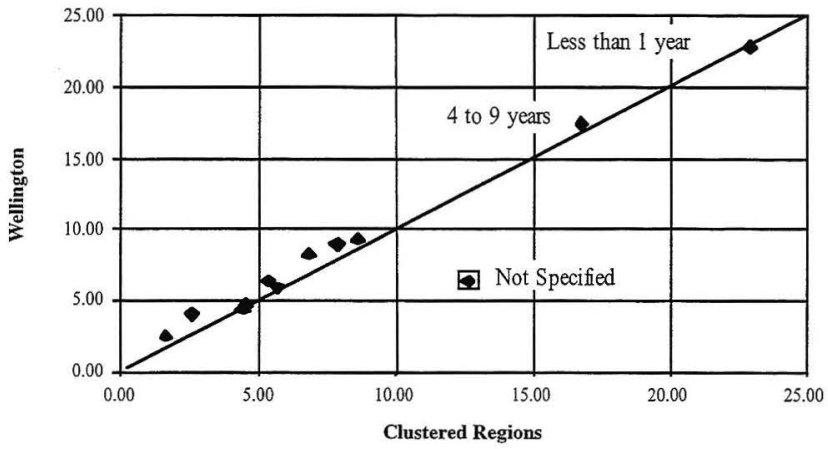

Pacific Islanders, which clearly increases in each successive census. In Wellington as a whole, European, Maori, and Pacific Island unemployment rates all fell in the period of recovery 1991-96. For the clustered areas however, these rates either generally stayed the same or increased. As well as variation in unemployment rates by ethnicity over the whole Wellington region, this data reveals that there is also significant variation within ethnic groups when divided into clustered and non-clustered areas.

The answer does not appear to lie with any differences in the age structure of the ethnic groups. If the clustered areas were by and large collections of young people, one would expect higher unemployment. There are slightly more young Maori and Pacific Island unemployed females than the rest of Wellington, but for males and all the data aggregated by ethnicity and sex, the age structure of the unemployed in the clustered areas is actually slightly older.

What does go some way to explaining the high and persistent unemployment rates within the clustered area is the fact that a significant proportion of the unemployed within these areas have no formal educational qualifications. In the clustered areas 50.75 percent of the unemployed have no for- mal educational qualification compared to 27.34 percent for the rest of Wellington. In every other category of highest qualification gained the clustered areas performed worse. What is surprising though, and in contrast to every other labour force indicator, is that the unemployment rate for those with no qualifications actually improved between 1991 and 1996 for both Wellington and the clustered areas (from 7.76 to 6.40 and 15.28 to 11.67 respectively). However, this may not be a result of the fact that more nonqualified unemployed in both areas gained jobs but simply because more unemployed gained qualifications.

Many studies have shown that spatial concentrations of unemployment go hand in hand with the location of social housing and areas that were previously centres of manufacturing employment. While all of the clustered areas found in this study were predominantly areas of state housing this did not seem to provide a good explanation of why unemployment had become so concentrated. There is no discernible relationship between the percentage of state houses in suburb and the suburbs unemployment rate.

Although the presence of state housing does not guarantee higher levels of unemployment there is within such areas

\section{Table 2. Unemployment rates by ethnicity for the clustered areas and the remainder of the Wellington region}

\begin{tabular}{|l|c|c|c|c|c|c|}
\hline & \multicolumn{2}{|c|}{$1986^{*}$} & \multicolumn{2}{c|}{1991} & \multicolumn{2}{c|}{1996} \\
\cline { 2 - 7 } & Clisters & Wgtn. & Clusters & Wgtn & Chster & Wgtn \\
\hline European & 6.77 & 5.09 & 10.53 & 6.80 & 9.55 & 5.16 \\
\hline Maori & 18.48 & 11.46 & 25.53 & 17.91 & 25.39 & 13.50 \\
\hline Pacific Islander & 15.01 & 10.43 & 21.95 & 16.20 & 27.25 & 12.23 \\
\hline
\end{tabular}

* 1986 data does not include part-time work 
an interesting relationship between the proportion of state houses and unemployment. For example, only once the percentage of state houses reaches 80 percent does unemployment appreciably rise. This suggests that there might be a threshold effect working that is actually consistent with a 'neighbourhood effects' hypothesis; once the percentage of state houses reaches a certain level within an area very few people employed in 'good' jobs will remain eligible to rent them. The employed labour force will shrink and the neighbourhood will gradually develop the types of externalities associated with concentrated unemployment.

As to the relationship within areas of dependence on manufacturing, while there is some evidence to suggest that the clustered areas were previously centres of manufacturing employment there is not enough to conclude that the fall in manufacturing employment in Wellington has contributed to the spatial clustering of the unemployed (although it has contributed to the overall increase in unemployment). A series of simple regressions were run on unemployment, employment in manufacturing, and employment in financial services to ascertain the effect of industrial restructuring on the location of unemployment, but no clear relationship was found between the percentage employed in manufacturing and the percentage unemployed in each area unit.

\section{Conclusion}

The intention of this research was to examine whether the observed spatial clustering of unemployment in the Wellington region was consistent with the notion of spatial hysteresis - the tendency for certain areas to retain high unemployment rates and clusters of unemployed even when city wide and national rates fall. The processes underlying spatial hysteresis were hypothesised to be linked to 'neighbourhood effects' - externalities associated with concentrations of non-work that tend to inhibit job search and attainment. The analysis was centered on the period of 1986 91 when unemployment rates across New Zealand were rising and on the 1991-96 recovery during which rates began to fall.

There is strong evidence from this study that over this recessionary/recovery period some from of spatial hysteresis has taken place. The extent of meshblock clustering, the intensity of clustering, unemployment rates, numbers of unemployed, and lack of labour force participation, have all increased throughout both the recessionary and recovery periods in the areas identified as containing significant clusters of unemployed.

Evidence for alternative explanations such as the spatial redistribution of population were weak given the available data. Similarly, while there are proportionally more Maori and Pacific Islanders unemployed in the clustered areas than in Wellington as a whole, each ethnic group performed equally badly or worse when compared to its Wellington wide distribution.

What can be said with certainty is that the probability of a person having neighbours, local friends, or local acquaint- ances unemployed or out of the labour force is far higher in the clustered regions than in the rest of Wellington. Also, this probability has increased in each successive census year since 1986 , with the spatial disparities in unemployment concentration increasing rather than decreasing during the recovery of 1991-96.

It is also apparent that the differences in the clustering of unemployment are not directly linked to the location of state housing. Even though the areas identified as significant clusters were all predominantly state housing suburbs, there was no discernible relationship between percentage of state housing within an area and it unemployment rate. Nor were areas of formerly high employment in manufacturing able to predict the clustering of unemployment.

In general this research has found that unemployment rates at a city level hide significant local variation. In the case of Wellington, the often touted performance of the local economy obscures the fact that spatial differences have increasingly led to a spatial concentration of the unemployed. Whether this is also associated with the isolation and attenuation of social networks so central to the notion of social exclusion and the theoretical concept of spatial hysteresis presented here, is a problem that must await detailed studies of individuals and households within the clusters identified by this research.

\section{Future research}

Social scientists are already giving far more attention to the effect of neighbourhoods on such factors as school achievement and labour market position, yet it is still not known how local residential environments can affect individuals' participation and performance in the local labour market.

The areas identified in this research require more intensive investigation as to the exact reasons for their lack of labour market performance. Census data needs to be complemented by other, more direct methods of investigation.

\section{Notes}

1. The LISA statistic employed for this study is $G_{i}^{*}$ (Getis and Ord, 1995). $\mathrm{G}_{i}{ }^{*}$ is a standard normal variate with mean 0 and standard deviation 1 . The equation defining $\mathrm{G}_{i} *$ is:

$$
\mathrm{G}_{i}^{*}=\frac{\sum_{j} w_{i j}(d) x_{j}-W_{i}^{*} x^{*}}{s^{*}\left\{\left[\left(n \mathrm{~S}_{1 i}{ }^{*}\right)-W_{i}^{* 2}\right] /(n-1)\right\}^{1 / 2}}
$$

where $w$ is a spatial weights vector (a vector of values that indicate the strength of the association between the central area and each of its neighbours) with values for all links defined as being within distance $d$ of a given $i$,

and:

$$
\begin{aligned}
& W_{i}=\sum_{j} w_{i j}(d), j=i \\
& W_{i}^{*}=W_{i}+w_{i i}
\end{aligned}
$$


and:

$S_{1 i}^{*}=\sum_{j} w_{i j}^{2}$, all $j$.

The mean is defined as:

$\mathrm{x}^{*}=\frac{\sum_{j} x_{j}}{n}$, all $j$

and the variance is:

$s^{* 2}=\frac{\sum_{j} x_{j}^{2}}{n} \cdot x^{* 2}$, all $j$.

The null hypothesis states that there is no association between the value $\mathrm{X}$ at a site $i$ and its neighbours, the $j$ s, up to and including a distance called $d$, measured from $i$ in all directions. Basically, the sum of values at all the $j$ sites within radius $d$ of $i$ is not more (or less) than one would expect by chance given all the values in the entire study area (both within and beyond $d$ ). If spatial autocorrelation exists, it will be exhibited by a spatial clustering of high or low values of $x$. When there is a preponderance of high values, the resulting $\mathrm{G}_{i}{ }^{*}$ will be positive. Low values yield a negative $\mathrm{G}_{i}^{*}$. Scott and Lloyd (1992) used this statistic to measure employment patterns in the greater Los Angeles area over the period 1980 to 1990.

2. Wellington's greater metropolitan area includes Upper Hutt, Lower Hutt, Porirua and Wellington City.

3. The 20 percent threshold was chosen on the basis of the distribution of unemployment in Wellington in 1986. During this year unemployment rates were considered to be very low and 20 percent was approximately three standard deviations away from the mean meshblock rate. Meshblocks with rates above this were considered to be extreme.

4. The unemployment rate was defined as the unemployed divided by the labour force (the unemployed plus the employed male and female populations).

5. Because the underlying distribution of rates was slightly skewed the test for significance had to be done with care. At $150 \mathrm{~m}$ the significance of the statistic is not that reliable due to the small number of neighbours. No significant clusters at $150 \mathrm{~m}$ however, are included in the results. Also, clusters that are close to each other in space tend to share common areas and are thus slightly correlated. This affects their independence and hence their significance. This was avoided by ensuring that each cluster had only one distinct centre even if it contained more than one meshblock with an unemployment rate that exceeded 20 percent.

6. Unfortunately SUPERMAP3, the census data package supplied by Statistics New Zealand, does not break down residence duration by labour force status at either the meshblock or area unit level. At the area unit level however, it does break down duration of residence by age group and sex. If the meshblock clusters are ap- proximated by area unit boundaries then the clustered areas duration of residence can be compared to that of the rest of Wellington.

7. Figure 3 reveals that in only one category does the clustered region's duration of residence profile differ significantly from that of Wellington; "Not Specified". This category however, may be important and highlights a common problem with census data - under reporting. It cannot be assumed that this category, if full information was available, would distribute itself evenly across the rest of the data. More likely, the people who do not participate in the census are probably prone to be far more transient in terms of jobs and residence causing the "Not Specified" category to contribute to an underrepresentation of short-term residence duration. Given the fact that the unemployed are likely to be the most transient and therefore more likely not to participate in the census, breaking down their census data by residential duration would probably result in a larger 'Not Specified' percentage and shed little light on the problem.

\section{References}

Baum S. and Hassan R. (1993) Economic Restructuring and Spatial Equity: a Case Study of Adelaide. Australian, New Zealand Joumal of Sociology, 29(2): 151-172.

Blanchard, O. J. and Summers, L. H. (1987) Hysteresis in Unemployment. European Economic Review, 31: 288-295.

Borooah, V. and Hart, M. (1995) Labour Market Outcomes and Economic Exclusion. Regional Studies 29.5: 433-438.

Callister, Paul (1997) Work-rich and Work-poor, individuals, families, households and communities: Changes between 1986 and 1996. Working paper presented at the Institute of Policy Studies, Victoria University of Wellington, 23 October, 1997.

Dangschat, Jens S. (1994) Concentration of Poverty in the Landscapes of 'Boomtown' Hamburg: The Creation of a new Urban Landscape? Urban Studies, 31(7): 1133-1147.

Fagan R.H. (1994) Working Nation and the Outer Suburbs: The Example of Western Sydney. Australian Geographer, 25(2): 115-121.

Greene, Richard (1990) Poverty Concentration Measures and the Urban Underclass. Economic Geography, 67: 240-252.

Gregory, R.G. and Hunter, B. (1995) The Macro Economy and the Growth of Ghettos and Urban Poverty in Australia. Research School of Social Sciences, Australian National University. Discussion Paper No. 325 .

Hughes, Mark A. (1987) Moving Up and Moving Out: Confusing Ends and Means About Ghetto Dispersal. Urban Studies, 24: 503-517. 
Jencks, C. \& Peterson P.E. (eds) (1991) The Urban Underclass. Washington, D.C: The Brookings Institute.

Kloosterman, Robert C. (1994) Amsterdamed: The Rise of Unemployment in Amsterdam in the 1980s. Urban Studies, 31(8): 1325-1344.

MacDonald, Robert (1997) Dangerous Youth and the Dangerous Class. In Robert MacDonald (ed.) Youth, the 'Underclass' and Social Exclusion. Routledge: London.

Mare, D. (1997) Labour Market Trends, Cycles, and Outlook. In Morrison P.S. (ed) Labour, Employment and Work in New Zealand. Proceedings from the Seventh Conference: 9-24.

McGregor, A. and McConnachie, M. (1995) Social Exclusion, Urban Regeneration and Economic Reintegration. Urban Studies 32(10): 1587-1600.

Mead, L.M. (1992) The New Politics of Poverty: the nonworking poor in America. New York: Basic Books.

Murphy P. and Watson S. (1993) Social Polarization and Australian Cities. International Journal of Urban and Regional Research, 17:571-590.

Murray, Charles (1990) The Emerging British Underclass. The IEA Health and Welfare Unit: London.

Neef, Rainer (1991) The New Poverty and Local Government Social Policies: A West German Perspective. Urban Studies 31(7):1133-1147

Wacquant, Loic J. D. (1993) Urban Outcasts: Stigma and Division in the Black American Ghetto and the French Urban Periphery. International Journal of Urban and Regional Research, 17: 366-383.

Wilson, J. (1987) The Truly Disadvantaged. Chicago: The University of Chicago Press.

\title{
Acknowledgments
}

I wish to acknowledge the financial support of Treasury in undertaking this Masters research. However, the author takes full responsibility for the views expressed in the paper.

\author{
Author \\ Paul Soldera is a Masters student with the \\ Institute of Geography, \\ School of Earth Sciences, \\ Victoria University of Wellington, \\ P.O. Box 600 , \\ Wellington.
}

